\title{
MUHURT GADNA (JYOTISH/ASTROLOGY) AND MICRO-TIME MANAGEMENT FOR STRESS REDUCTION
}

\author{
Dr. Nishi Arora ${ }^{*}{ }^{\square}$, Dr. Nidhi Shrivastava ${ }^{2}$, Ravi Shrivastav ${ }^{3}$ \\ ${ }^{1}$ Associate Professor H.O.D, Maulik Siddhant and Samhita Vibhag, A\&U Tibbia College and \\ Hospital, New Delhi, India \\ ${ }^{2}$ Associate Professor and Head of Department, Sharir Rachna Vibhag, Government Ayurveda \\ College, Jabalpur M.P., India \\ ${ }^{3}$ Associate Professor and Head of Department, Agad Tantra \& Vyavhar Ayurveda Vibhag, \\ Government Ayurveda College, Jabalpur M.P., India
}

DOI: https://doi.org/10.29121/granthaalayah.v8.i8.2020.1271

Article Type: Research Article

Article Citation: Dr. Nishi Arora, Dr. Nidhi Shrivastava, and Ravi Shrivastav. (2020). MUHURT GADNA (JYOTISH/ASTROLOGY) AND MICRO-TIME MANAGEMENT FOR STRESS REDUCTION. International Journal of Research GRANTHAALAYAH, 8(8), 386-388. https://doi.org/10.29121/granthaa layah.v8.i8.2020.1271

Received Date: 15 August 2020

Accepted Date: 31 August 2020

\section{Keywords:}

Muhurt

Jyotish

Micro-Time Management

\begin{abstract}
Considering the fact, that 'Time' is the most important factor in human's life, the author decided to work upon Muhurt gadna (micro-time calculation) and modern time management techniques to find a wayout for prevailing stress in the society. In this paper, ancient Indian texts of Jyotish (Astrology) were explored for the concept of Muhurt gadna. The author had gone through modern psychology books for time management skills. In this paper definition and reasons of stress are given. Importance of time management in reducing stress is also described. In the end it is concluded that ancient system of micro-time management with Muhurt gadna may prove a better option to reduce the stress and also to increase probability of achieving the goals.
\end{abstract}

\section{INTRODUCTION}

One thing that's missing in all hustles and bustles of today's life is "Time". It is a factor that decides everything of a human being; right from the birth to whole life span. Unfortunately, the men forget its importance, she or he always remains busy with one thing or the other. "I have no time to sit back with my family." "I have no time for my routine exercise schedule." "I have no time for self-analysis." The list of these kinds of statements is infinite. Every second person complains of unlimited stress without specific reason. Considering the need of the hour, the author of this article decided to work upon management of time and its impact on stress reduction.

Journey of the author started from the age back science of Bharat i.e. Jyotish Shastra (Astrology). It was a great surprise to learn about Muhurt gadna. Dividing a day and night into time slots of thirty Muhurts (a measurement unit of time, in those times) was a great research. All the Muhurts were named and their characteristic features were

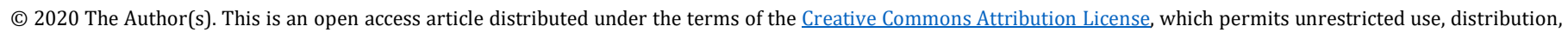
and reproduction in any medium, provided the original author and source are credited. 
also explored. Specific time slot was designated for a specific purpose. It was really interesting to know about such micro-management of time.

Taking inspiration from the above facts, the author studied contemporary time- management practices. It was found that time-management can be an important tool in reduction of stress. The following paper would throw some light on this aspect of stress management through regulation of time.

\section{MATERIALS AND METHODS}

To understand more about Muhurt Gadna (Calculation of the time slot) the author took help from Muhurt Chintamani [1], Jyotish Tattvank [2] and information available on Wikipedia [3]. The author also received modern psychology books for finding out relationship of time management and stress management. First, let's have a short overview about Muhurt. It is an ancient unit of measurement for time along with Nimesh, Kashta and Kala. From etymology point of view, it breaks itself into two parts "muhu" (moment/immediate) and "rta" (order). The author of Rigved (111.33.5) has accordingly created this descriptive term. Rta refers to the natural, yearly order of the seasons, so that the term "Muhurt" refers to the daily reflection of these. In Brihat Samhita (Bri.Sa-1/8) [4], it is clearly said that no time is auspicious or inauspicious, but due to the climatic changes and movement of planets at a particular moment, the good or bad outcomes are seen. The concept is based upon minute travel details of sun and the other planets of the orbit. In a way it was a great deal of micro- calculation of time. With this, the goals used to be set according to the probable change of the natural setting and most of the times; the clarity about reaching the goal could be sorted out. It made their lives simpler.

In modern time also it is said that time management is essential to be hassle free and for lowering down the stress in daily life. Before going ahead, definition of "stress" and time management has to be seen. 'Stress is a state of mental or emotional strain or tention resulting from adverse or demanding circumstance [5]. "Time management" is the process of organizing how to divide your time between specific activities [6]. With these definitions, the author could frame some facts like - stress generally occurs of demanding circumstances, and the person feels lack of productivity even after a plenty of time devotion in terms of mental and physical abilities. Unfulfilled goals lead to emotional as well as mental strain. The circumstances seem to be against when one counters missed guidelines, inefficient work flow, poor work qualify, poor professional reputation etc. All then lead to high levels of stress with the help of time management, one may sort out the above issues with prioritizing the tasks, keeping a daily dairy log, identifying the time wasters and wise use of discretory time which send to better accomplishment of goal [7].

\section{DISCUSSION}

All that is revealed is enough to understand that there is definitely a relation between time management and stress reduction. The second thing that is clear in modern times, time is being managed as gross parameters. Like time to wake up in the morning, having breakfast, time to sleep, maintaining dairy or logs etc. to full fill the demand of the hour. Definitely it is very important to manage this way and regulate the life through discipline. On the other hand, the ancient Bhartiya Science of 'Jyotish' speaks about micro time management. It means there was a trend to work on minute to minute plan as is depicted through meaning of 'muhu' in 'muhurt'. Second thing is that they also considered 'Ritu' or season for a particular task to be done. In the ancient scientific analysis, the probability of achieving the goal was bigger than today's principles of Time management.

Modern time management does not say much about right time to getting married or taking major life changing decisions. But in Muhurt gadna principle, smallest to largest decisions were used to make accordingly to measurement of the smallest unit of time. This used to provide the direction at each step. It was nothing like superstition or blind faith. It was based on a planetary science. The people of that age, used to give equal importance to the nature, as they gave it to themselves. All these measures reduce the stress, as they behold the strength of science and trust both.

\section{CONCLUSION}

Muhurt gadna or micro time calculation was a great science. With the help of this principle the people used to decide their goals and work accordingly. Even today, Muhurt are calculated in 'Bharat' for marriage, or bhumi pujan 
like rituals. But it's time to explore the concept in more practical way. This micro-management habit inculcation may show path for better results in daily life stress management as well as in psychological stress management methods, where stress leads to anxiety and the third step in depression. Gross time management is also a method to increase efficiency and better life style practice.

Good time management requires an important shift in focus from activities to result. Being busy isn't the same as being effective. Effectivity reduces the levels of stress and over thinking or excessively straining the body and mind.

\section{SOURCES OF FUNDING}

This research received no specific grant from any funding agency in the public, commercial, or not-for-profit sectors.

\section{CONFLICT OF INTEREST}

The author have declared that no competing interests exist.

\section{ACKNOWLEDGMENT}

None.

\section{REFERENCES}

[1] Muhurt Chintamani - Daivagya Shri Ramacharyavirachit, Khemraj Shri krishnadasane, Mumbai, samvat 1984

[2] Kalyan Jyotish tattvank, Gita Press, Gorakhpur, Yr.1980

[3] https://en.in.wikipedia.org.downloaded on 25/8/2020

[4] Vrihat Samhita, Adhyay 1/8, Gita Press, Gorakhpur.

[5] Oxford dictionary

[6] English language dictionary

[7] Mind tools.com downloaded on 25/8/2020 